\title{
Monitoring the Presence of 13 Active Compounds in Surface Water Collected from Rural Areas in Northwestern Spain
}

\author{
Alejandra Iglesias ${ }^{1}$, Carolina Nebot ${ }^{1, *}$, Beatriz I. Vázquez ${ }^{1}$, Claudia Coronel-Olivares ${ }^{2}$, \\ Carlos M. Franco Abuín ${ }^{1}$ and Alberto Cepeda ${ }^{1}$
}

1 Department of Analytical Chemistry, Nutrition and Bromatology, Faculty of Veterinary Medicine, University of Santiago de Compostela, Lugo 27002, Spain; E-Mails: alejandra.iglesias@usc.es (A.I.); beatriz.vazquez@usc.es (B.I.V.); carlos.franco@usc.es (C.M.F.A.); alberto.cepeda@usc.es (A.C.)

2 Instituto de Ciencias Básicas e Ingeniería, Área Académica de Química, Universidad Autónoma del Estado de Hidalgo, Carretera Pachuca-Tulancingo Km. 4.5, Ciudad del Conocimiento, Mineral de la Reforma, Hidalgo 42184, Mexico; E-Mail: ccoronel@uaeh.edu.mx

* Author to whom correspondence should be addressed; E-Mail: carolina.nebot@usc.es; Tel.: +34-982-285-900; Fax: +34-982-254-592.

Received: 10 February 2014; in revised form: 16 April 2014 / Accepted: 8 May 2014 / Published: 15 May 2014

\begin{abstract}
Drug residues are considered environmental contaminants, and their occurrence has recently become a matter of concern. Analytical methods and monitoring systems are therefore required to control the continuous input of these drug residues into the environment. This article presents a suitable HPLC-ESI-MS/MS method for the simultaneous extraction, detection and quantification of residues of 13 drugs (antimicrobials, glucocorticosteroids, anti-inflammatories, anti-hypertensives, anti-cancer drugs and triphenylmethane dyes) in surface water. A monitoring study with 549 water samples was carried out in northwestern Spain to detect the presence of drug residues over two sampling periods during 2010, 2011 and 2012. Samples were collected from rural areas with and without farming activity and from urban areas. The 13 analytes were detected, and $18 \%$ of the samples collected showed positive results for the presence of at least one analyte. More collection sites were located in rural areas than in urban areas. However, more positive samples with higher concentrations and a larger number of analytes were detected in samples collected from sites located after the discharge of a WWTP. Results indicated that the
\end{abstract}


WWTPs seems to act as a concentration point. Positive samples were also detected at a site located near a drinking water treatment plant.

Keywords: drugs; urban; rural; LC-MS/MS; environmental water; Spain

\section{Introduction}

Around the world, drugs consumption in both human and veterinary medicine has been increasing year after year. The consumption of pharmaceuticals in the EU is substantial, with approximately 3,000 different active substances such as analgesics and anti-inflammatory drugs, contraceptives, antibiotics, beta-blockers, lipid regulators and neuroactive compounds being commonly used in human medicine [1]. These compounds enter the environment through many routes, including manufacturing, formulation, distribution, use and disposal. The use of pharmaceuticals by individuals is the main route. After ingestion, metabolites or drugs that are not completely metabolised in the body are expelled in faeces or urine and reach drains. Wastewater treatment plants (WWTPs) have no specific technologies to eliminate drugs entirely from the waste stream, so active compounds (drugs and metabolites) enter the aquatic environment straightforward from the effluents are discharged daily into rivers, making these residues pseudo-persistent pollutants. Pharmaceuticals widely used in the treatment of animals such as the antimicrobials, sulfonamides and quinolones can also be employed in the treatment of human infections. These drugs could be released directly to the environment through the extensive livestock-raising operations and can accumulate in manure pits or livestock waste that may be used to fertilise agricultural lands [2]. The result of these practices is that any residues of drug administered reach via runoff, rivers, lakes and seas and via filtration, groundwater, aquifers and wells. The direct contamination of aquatic environments by aquaculture can lead to the exposure of aquatic and sediment dwelling organisms to the contaminants [3]. The triphenylmethane dyes, malachite green (MG) and brilliant green (BG), originally used as dyeing agents in the textile and paper industries, are also observed as contaminants of the aquatic environment. The dyes were introduced illegally in 1933 as ecto-parasiticides, fungicides and antiseptics in aquaculture because of their broad fungicidal and antiparasitical activity, and the dyes are effective against Gram-positive microorganisms [4]. However, $\mathrm{MG}$ and $\mathrm{BG}$ are toxic to multiple organs in mammals and have negative effects on the immune and reproductive systems as well as genotoxic and carcinogenic properties [5,6], so their use in aquaculture is forbidden.

The reason for the development of interest in the research is that reports on the occurrence of pharmaceuticals in the aquatic environment show that the pharmaceuticals are ubiquitous. The continued input of these compounds into the environment, even at low concentrations, potentially serves to sustain chronic exposure for aquatic organisms [7]. Toxic effects in non-target organisms have previously been reported by Jung et al., Kim et al., Li et al. and Madureira et al. [8-11]. Sulfonamides, propanolol, trimethoprim and diclofenac, inter alia, have been demonstrated to exert toxicity on plants, soil organisms, freshwater crustaceans, fish and zebrafish.

Pharmaceutical pollutants are being discharged daily and continuously, albeit their detection in the aquatic environment can be complicated because these compounds are typically present at levels of ng $\cdot \mathrm{L}^{-1}$ 
and $\mathrm{pg} \cdot \mathrm{L}^{-1}[7,12]$. Detection of pharmaceuticals is influenced by the different properties of the multiple classes of drugs. Specific and suitable methods therefore need to be developed to identify and quantify the drugs in the aquatic environment. The analytical methods employed for the analysis of drugs are also varied, and the sample preparation procedure generally involves the use of large sample volumes, multiple extractions, sophisticated sample clean up, and/or derivatisation prior to analysis. Following extraction, depending on the nature of the target compound, pharmaceuticals are identified and quantified using a variety of analytical instruments. Analytical techniques including high performance liquid chromatography (HPLC) and gas chromatography (GC) allow the analysis of multiple analytes in the same extract when coupled to a mass spectrometer (MS), the combination of these techniques is commonly employed in environmental analyses [13-19]. However, detectors other than MS such as ultraviolet (UV), fluorescence (FL), chemiluminescence (CL) and other techniques such as capillary electrophoresis (CE) are also employed [20-25].

In the Mediterranean area of Spain, pharmaceuticals such as antimicrobials and anti-inflammatories and other compounds such as drugs of abuse have been reported several times in the 21st century [26-31]. The presence of pharmaceuticals has also been reported in Sevilla, Madrid and Galicia [32-34] surface waters. However, none of the publications cited, to the author's knowledge, have previously investigated the presence of antimicrobials, anti-hypertensives, anti-cancer drugs, corticosteroids, anti-inflammatories and triphenylmethane dyes in river water samples, simultaneously. The geographical area investigated in this work contains the most important river in the Galician area, running through areas with high population density as well as areas dedicated to agriculture and livestock, thus indicating the importance of this community in the production of food from animal and vegetable origins. Because there are trout farms and paper industries in the sampling area, the possibility of finding residues of $\mathrm{MG}$ and $\mathrm{BG}$ in the aquatic environment must be considered.

The aim of this work is to present a method using HPLC-MS/MS for the simultaneous identification and quantification of 13 target compounds (seven antimicrobials, one anti-hypertensive, one anticancer drug, one synthetic corticosteroid, one non steroidal anti-inflammatory and two triphenylmethane dyes) in surface water. In particular, diclofenac, sulfamethoxazole, trimethoprim and oxolinic acid were included in the study because they are drugs commonly used in human medicine and their presence in environmental waters has been reported by different authors [14,17,32].

The assessment of the level of pollution generated in the production of food from animal origin derived from the use of the selected drugs has been carried out by analyzing water samples collected from rural areas with high and low density of farming activities. Urban areas located close to the discharge of WWTPs, were included in the study for comparison and based on the common presence of some of the drugs in these types of sampling points. Therefore, the method was validated in house and has been applied to the analysis of 549 surface water samples collected in rural and urban areas of the Galician environment during two different sampling periods. 


\section{Experimental Section}

\subsection{Chemicals, Reagents and Stock Solutions}

Brilliant green, diclofenac, difloxacin, enrofloxacin, malachite green, marbofloxacin, oxolinic acid, propanolol, sarafloxacin, sulfamethoxazole, tamoxifen, triamcinolone and trimethoprim (all purity $>98 \%$ ) and the internal standards (ISs) sulfadoxine- $\mathrm{d}_{3}$ and malachite green- $\mathrm{d}_{5}$ picrate were purchased from Sigma-Aldrich (St. Louis, MO, USA). All the therapeutic and chemical properties of the selected drugs are presented in Table 1. Methanol (HPLC-grade, $\geq 99.9 \%$ ) was obtained from Scharlau Chemie (Barcelona, Spain), and formic acid (purity $>99 \%$ for analysis) was purchased from Acros Organics (Geel, Belgium). Hydrochloric acid solution (1 N HCl) was purchased from Merck (Darmstadt, Germany). Purified water was prepared in house with a Milli-Q water system from Millipore (Bedford, MA, USA), and nitrogen gas (purity $>99.98 \%$ ) was generated by an in-house nitrogen generator from Peak Scientific Instruments Ltd. (Chicago, IL, USA).

Table 1. Therapeutic class and chemical properties of the selected drugs.

\begin{tabular}{llll}
\hline Analyte & Therapeutic Class & CAS Number & Formula \\
\hline Brilliant Green & Triphenylmethane dye & $633-03-4$ & $\mathrm{C}_{27} \mathrm{H}_{34} \mathrm{~N}_{2} \mathrm{O}_{4} \mathrm{~S}$ \\
Diclofenac & Anti-inflammatory & $15307-79-6$ & $\mathrm{C}_{14} \mathrm{H}_{11} \mathrm{Cl}_{2} \mathrm{NO}_{2}$ \\
Difloxacin & Antimicrobial & $98106-17-3$ & $\mathrm{C}_{21} \mathrm{H}_{19} \mathrm{~F}_{2} \mathrm{~N}_{3} \mathrm{O}_{3}$ \\
Enrofloxacin & Antimicrobial & $93106-60-6$ & $\mathrm{C}_{19} \mathrm{H}_{22} \mathrm{FN}_{3} \mathrm{O}_{3}$ \\
Malachite Green & Triphenylmethane dye & $2437-29-8$ & $\mathrm{C}_{23} \mathrm{H}_{25} \mathrm{ClN}_{2}$ \\
Marbofloxacin & Antimicrobial & $115550-35-1$ & $\mathrm{C}_{17} \mathrm{H}_{19} \mathrm{FN}_{4} \mathrm{O}_{4}$ \\
Oxolinic Acid & Antimicrobial & $14698-29-4$ & $\mathrm{C}_{13} \mathrm{H}_{11} \mathrm{NO}_{5}$ \\
Propanolol & Anti-hypertensive & $525-66-6$ & $\mathrm{C}_{16} \mathrm{H}_{21} \mathrm{NO}_{2}$ \\
Sarafloxacin & Antimicrobial & $98105-99-8$ & $\mathrm{C}_{20} \mathrm{H}_{17} \mathrm{~F}_{2} \mathrm{~N}_{3} \mathrm{O}_{3}$ \\
Sulfamethoxazole & Antimicrobial & $723-46-6$ & $\mathrm{C}_{10} \mathrm{H}_{11} \mathrm{~N}_{3} \mathrm{O}_{3} \mathrm{~S}$ \\
Tamoxifen & Anti-cancer & $10540-29-1$ & $\mathrm{C}_{26} \mathrm{H}_{29} \mathrm{NO}^{2}$ \\
Triamcinolone & Glucocorticoid & $124-94-7$ & $\mathrm{C}_{21} \mathrm{H}_{27} \mathrm{FO}_{6}$ \\
Trimethoprim & Antimicrobial & $738-70-5$ & $\mathrm{C}_{14} \mathrm{H}_{18} \mathrm{~N}_{4} \mathrm{O}_{3}$ \\
\hline
\end{tabular}

The drugs were accurately weighed $( \pm 0.0001 \mathrm{~g})$ on an analytical balance from Ohaus ${ }^{\circledR}$ GA200 (Nänikon, Switzerland) to prepare stock solutions of individual compounds at a concentration of $0.6 \mathrm{mg} \cdot \mathrm{mL}^{-1}$ in methanol. These stock solutions were mixed with $0.1 \%$ of formic acid in methanol to obtain a stock solution of $1 \mu \mathrm{g} \cdot \mathrm{mL}^{-1}$, and this solution was further diluted with $0.1 \%$ of formic acid in methanol to obtain standard mixtures of drugs at $12.5,25,50,75,100$ and $150 \mathrm{ng} \cdot \mathrm{mL}^{-1}$. The stock solutions of the ISs (sulfadoxine- $\mathrm{d}_{3}$ and malachite green- $\mathrm{d}_{5}$ picrate) at $0.6 \mathrm{mg} \cdot \mathrm{mL}^{-1}$ were mixed to obtain a working stock solution of $1 \mu \mathrm{g} \cdot \mathrm{mL}^{-1}$ with $0.1 \%$ formic acid in methanol. All of the standard solutions were stored in the dark at $-18{ }^{\circ} \mathrm{C}$ for a maximum of six months.

\subsection{Equipment}

Samples were analysed on an HPLC-MS/MS system consisting of an HPLC model 1200 G1312A from Agilent Technologies (Waldbronn, Germany) with a binary pump, a degasser and an autosampler. The MS was a model API 4000 ${ }^{\mathrm{TM}}$ from Applied Biosystems MSD Sciex Instruments (Toronto, ON, 
Canada) with an integrated TurboIonSpray ${ }^{\circledR}$ for molecule ionisation. The software Analyst 1.4.1, also from Applied Biosystems, MSD Sciex, was employed to acquire the data and control the system.

The chromatographic analyses were performed by injecting $10 \mu \mathrm{L}$ of the extract into a Synergi $2.5 \mu \mathrm{m}$ Polar-RP 100A column $(50 \times 2.0 \mathrm{~mm})$ connected to a Polar-RP security-guard cartridge $(4.0 \times 2.0 \mathrm{~mm})$, which were both obtained from Phenomenex (Macclesfield, UK). An MS2 Minishaker vortex mixer from IKA ${ }^{\circledR}$ (Staufen, Germany) and a vacuum station manifold with Strata ${ }^{\circledR}$-X solid phase extraction (SPE) cartridges $(60 \mathrm{mg}, 3 \mathrm{~mL})$, which were both obtained from Phenomenex (Macclesfield, UK), and a TurboVap ${ }^{\circledR}$ II evaporator from Zyrmark (Hopkinton, MA, USA) were employed for sample preparation and extraction.

The physical and chemical parameters (nitrites, ammonium, conductivity, turbidity and $\mathrm{pH}$ ) were measured for each collected sample. These analyses utilised the following equipment and kits: Visocolor $^{\circledR}$ ECO nitrite test $\left(0.02-0.5 \mathrm{mg} \cdot \mathrm{L}^{-1} \mathrm{NO}_{2}{ }^{-}\right)$and ammonium $3\left(0.2-3 \mathrm{mg} \cdot \mathrm{L}^{-1} \mathrm{NH}^{4+}\right)$, both from Macherey-Nagel $\mathrm{GmbH} \&$ Co. KG (Düren, Germany); a conductivity meter model CON6/TDS6 (Hand-held Conductivity/TDS Meter) from Eutech Instruments Pte. Ltd./Oakton Instruments (Illinois, IL, USA); a turbidimeter model TN-100 from Eutech Instruments Pte. Ltd. (Singapore, Singapore); and a pH meter model MicropH 2000 from Crison (Barcelona, Spain).

\subsection{HPLC-MS/MS Conditions}

Separation of analytes was achieved using a gradient mixture of two components, A $(0.1 \%$ formic acid in water) and B (0.1\% formic acid in methanol). The gradient programme employed is shown in Table 2, and the flow rate was $0.2 \mathrm{~mL} \cdot \mathrm{min}^{-1}$ during the whole run.

Table 2. Gradient program of the HPLC-MS/MS method developed.

\begin{tabular}{ccc}
\hline Total Time (min) & Mobile Phase A (\%) & Mobile Phase B (\%) \\
\hline 0 & 90 & 10 \\
2 & 90 & 10 \\
7 & 50 & 50 \\
15 & 25 & 75 \\
24 & 0 & 100 \\
28 & 0 & 100 \\
33 & 75 & 25 \\
36 & 90 & 10 \\
40 & 90 & 10 \\
\hline Notes: A: $0.1 \%$ formic acid in water; B: $0.1 \%$ formic acid in methanol.
\end{tabular}

Mass spectrometric measurements were performed using positive electrospray ionisation ( $\mathrm{ESI}^{+}$), and drug identification was performed using two multiple reaction monitoring (MRM) transitions and their retention times $\left(t_{R}\right)$. Standard solutions of the individual drugs in a concentration of $1 \mu \mathrm{g} \cdot \mathrm{mL}^{-1}$ in $0.1 \%$ formic acid in methanol were infused directly into the mass spectrometer, using a $1 \mathrm{~mL}$ syringe pump (model Gastight ${ }^{\circledR} 1001$ ), which was purchased from Hamilton (Bonaduz, Switzerland), at a flow rate of $5 \mu \mathrm{L} \cdot \mathrm{min}^{-1}$. The optimum cone voltage and collision gas energy were selected when they gave the most intense signals. Then, the HPLC with a Synergy-Polar column was connected to the MS. 
To monitor a specific transition between a precursor and a product ion, the following MS parameters needed to be set: declustering potential (DP), entrance potential (EP), collision energy (CE) and cell exit potential (CXP). These parameters varied for each compound and changed automatically during the run, as summarised in Table 3. The following MS parameters were kept constant during the run: a source temperature of $650{ }^{\circ} \mathrm{C}$, a vacuum gauge of $4.1 \cdot 10^{-5}$ Torr, an ion spray voltage of $5,000 \mathrm{~V}$ and a curtain gas pressure of $12 \mathrm{psi}$. The first ion source was set at $45 \mathrm{psi}$, and the second ion source was set at 50 psi. For all monitored transitions, the dwell time was $10 \mathrm{~ms}$.

Table 3. Retention time $\left(t_{R}\right)$, precursor and product ions and MS parameters employed to identify the selected drugs.

\begin{tabular}{|c|c|c|c|c|c|c|c|c|}
\hline \multirow{2}{*}{ Analyte } & \multirow{2}{*}{$t_{R}(\min )$} & \multirow{2}{*}{$\begin{array}{c}\text { Precursor } \\
(m / z)\end{array}$} & \multirow{2}{*}{$\begin{array}{c}\text { Product } 1 \\
(m / z)\end{array}$} & \multirow{2}{*}{$\begin{array}{c}\text { Product } 2 \\
(m / z)\end{array}$} & \multicolumn{4}{|c|}{ Precursor $>$ Product Ion 1} \\
\hline & & & & & DP & EP & $\mathbf{C E}$ & CXP \\
\hline Brilliant Green & 34.09 & 385 & 341 & 241 & 61 & 10 & 53 & 10 \\
\hline Diclofenac & 20.29 & 296 & 214 & 250 & 51 & 10 & 43 & 14 \\
\hline Difloxacin & 15.44 & 400 & 299 & 356 & 71 & 10 & 27 & 32 \\
\hline Enrofloxacin & 14.91 & 360 & 316 & 342 & 76 & 10 & 28 & 8 \\
\hline Malachite Green & 25.12 & 329 & 208 & 165 & 111 & 10 & 43 & 18 \\
\hline Marbofloxacin & 13.74 & 363 & 72 & 320 & 76 & 10 & 51 & 4 \\
\hline Oxolinic Acid & 16.62 & 262 & 216 & 160 & 36 & 10 & 39 & 14 \\
\hline Propanolol & 15.97 & 260 & 116 & 183 & 106 & 10 & 23 & 10 \\
\hline Sarafloxacin & 16.05 & 386 & 342 & 299 & 76 & 10 & 23 & 22 \\
\hline Sulfamethoxazole & 13.20 & 254 & 156 & 92 & 81 & 10 & 25 & 14 \\
\hline Tamoxifen & 21.2 & 372 & 340 & 235 & 106 & 10 & 73 & 14 \\
\hline Triamcinolone & 15.34 & 395 & 375 & 357 & 66 & 10 & 15 & 6 \\
\hline Trimethoprim & 12.05 & 291 & 230 & 123 & 56 & 10 & 35 & 20 \\
\hline Sulfadoxine $d_{3}$ & 13.70 & 314 & 156 & 108 & 41 & 10 & 27 & 12 \\
\hline Malachite green $d_{5}$ picrate & 25.8 & 334 & 213 & 170 & 126 & 10 & 47 & 24 \\
\hline
\end{tabular}

Notes: DP: Declustering potential; EP: Entrance potential; CE: collision energy; CXP: cell exit potential.

\subsection{Study Site Description}

The geographical area investigated is located in the extreme northwest (NW) portion of the Iberian Peninsula, just north of Portugal. The Miño River is an international river with a length of approximately $340 \mathrm{~km}$. The source of the Miño River lies in Pedregal of Irimia, which is $50 \mathrm{~km}$ north of Lugo in Galicia, Spain (Serra de Meira, Lugo, at $750 \mathrm{~m}$ elevation) and in the last $75 \mathrm{~km}$, the river defines the border between Portugal and Spain. The Miño River is the most important drainage basin in NW Spain, extending over $17,757 \mathrm{~km}^{2}$ with abundant areas dedicated to agriculture and livestock distributed along its path to the Atlantic Ocean [35]. The landscape of Galicia is dominated by the valleys created by the Miño River and its tributaries. Samples were collected from the Miño River and one of its main tributaries, the Asma River. The study area encompassed the upper basin, which includes the metropolitan area of Lugo, with approximately 98,000 residents (INE 2011) and areas dedicated to agriculture and farm production. 


\subsection{Sampling Strategy, Method and Conservation}

Our sampling strategy was designed based on previous work where veterinary drugs were investigated in river water from different areas with and without farming activity using a total of 14 sampling points. Six of the points were located in rural areas and the other eight were chosen at different points along the Miño River, Galicia's largest river, which goes across both rural and urban areas (Figure 1).

Figure 1. Locations of the sampling sites selected for the monitoring study.

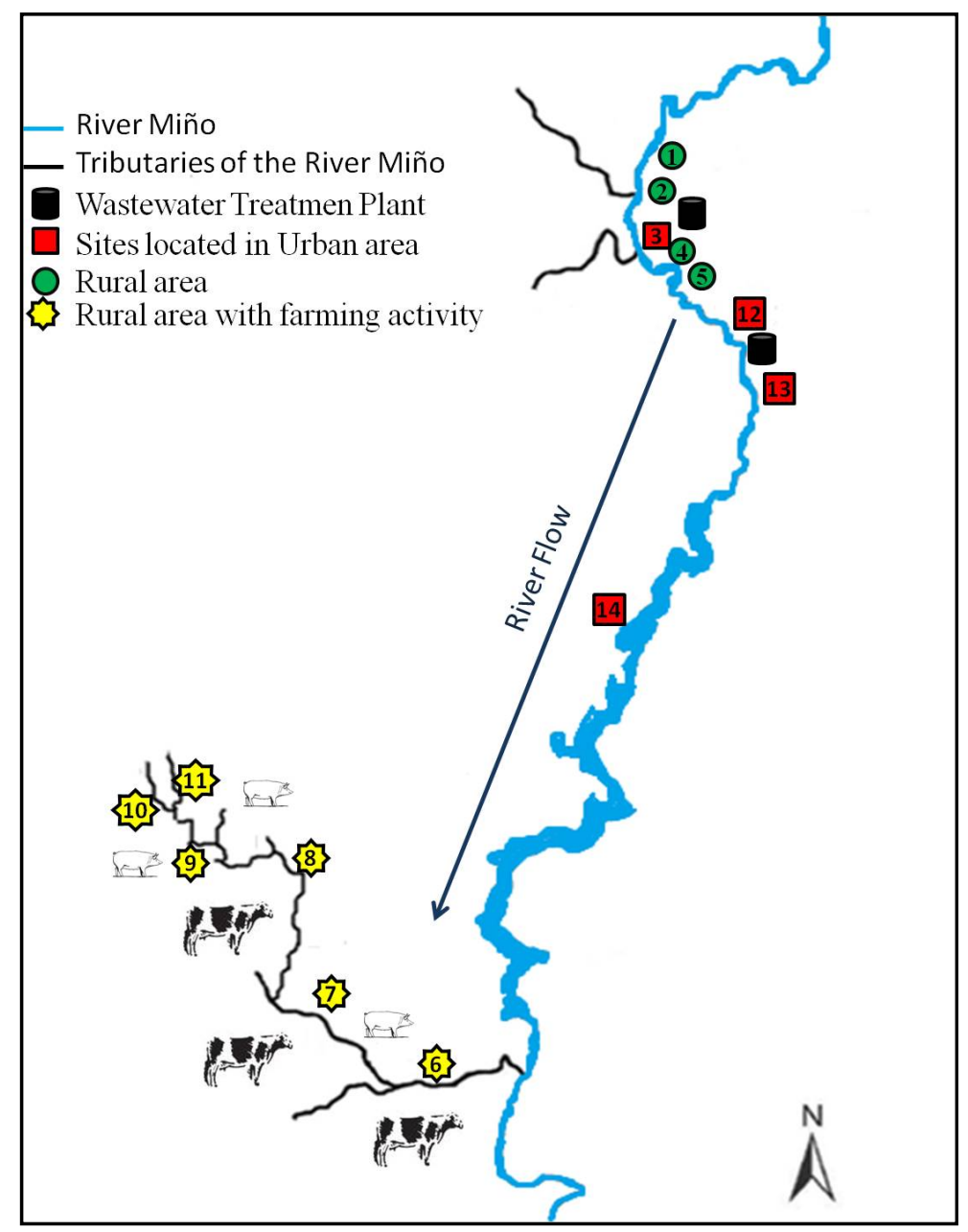

The method was developed and validated with river water samples collected from the Miño River, and the monitoring study was conducted with Galician fresh water. A total of 267 river samples of 1-L were collected in 1-L polyethylene plastic vessels during two different sampling periods, the first sampling period over a nine-week period from October to December 2010 and the second sampling period over a seven-month period between November 2011 and May 2012. The sampling sites were distributed along the Miño River between the villages of Rábade and Chantada in the province of Lugo. Of a total of 14 points, eight were located at the Miño River, one in its tributary the Asma River and five in streams and brooks (Figure 1).

All the samples for method validation and monitoring studies were filtered upon arrival at the laboratory and divided into replicate samples of $500 \mathrm{~mL}$ and were stored at $4{ }^{\circ} \mathrm{C}$ until analysis was carried out, which was always performed the day after sampling. The extracts were stored at $-18{ }^{\circ} \mathrm{C}$ 
until their HPLC-MS/MS analysis was performed which took place within no more than seven days after the extraction. To quantify the analytes correctly all the river water samples were spiked with $50 \mu \mathrm{L}$ of the IS solution and a blank and two control samples (Milli-Q water and Milli-Q water samples spiked at 75 and $150 \mathrm{ng} / \mathrm{L}$, respectively) were filtered, stored and processed in the same way as our natural water samples for identification of contamination risk during sample processing.

\subsection{Analytical Procedure}

Analytical determinations were carried out using a modification of a previously reported method [36] based on solid-phase extraction (SPE) and determination by high performance liquid chromatography coupled to tandem mass spectrometry. Filtered samples were acidified with $1 \mathrm{~N} \mathrm{HCl}$ solution to a $\mathrm{pH}$ of 3 and loaded in to a SPE cartridge (Strata ${ }^{\circledR}-\mathrm{X}$, Phenomenex, Torrance, CA, USA) activated with $4 \mathrm{~mL}$ of methanol and $4 \mathrm{~mL}$ of water at $\mathrm{pH} 3$. The analytes were eluted with $8 \mathrm{~mL}$ of methanol and evaporated to dryness under a nitrogen stream at $45^{\circ} \mathrm{C}$. The extracts were reconstituted with $200 \mu \mathrm{L}$ of $0.1 \%$ formic acid in methanol and stored at $-18{ }^{\circ} \mathrm{C}$ until further analysis by HPLC-MS/MS. The extracts were analysed within one week following extraction.

The samples employed for the determination of physical and chemical parameters (nitrites, ammonium, conductivity, turbidity and $\mathrm{pH}$ ) were stored at $4{ }^{\circ} \mathrm{C}$ in the laboratory until analysis, which was carried out within one day of sampling. The physical and chemical parameters were determined following the manufacturers' instructions for the respective kits and equipment.

\subsection{Validation Procedure}

As the method employed is a modification of a previously reported method, validation had to be performed.

The linear response of the instrument to standard solutions containing all the selected drugs at six different concentrations $\left(1,5,10,50,100\right.$ and $\left.200 \mathrm{ng} \cdot \mathrm{mL}^{-1}\right)$ was investigated. These standard solutions were employed to obtain the instrument calibration curves (ICCs). The instrument detection limit (IDL) was defined as the concentration that gave a signal-to-noise $(\mathrm{S} / \mathrm{N})$ ratio above 3 , and the instrument quantification limit (IQL) was defined as the concentration that gave an $\mathrm{S} / \mathrm{N}$ above 10 . The linearity of the whole method, extraction and HPLC-MS/MS detection, was evaluated using matrix-matched samples with river water samples spiked with all the selected drugs at the following concentrations: $1,5,10,20,50,75,100,150$ and $200 \mathrm{ng} \cdot \mathrm{L}^{-1}$. These samples were employed to build sample calibration curves (SCCs) and to determine the limit of detection (LOD) for the method, which is defined as the lowest concentration that gave an $\mathrm{S} / \mathrm{N}$ above 3 and a method limit of quantification (LOQ) at an S/N above 10. Once the LOD was established, the method detection limit (MDL) was also calculated following the Environmental Protection Agency (EPA) procedure from CFR 136, Appendix B criteria [37]. The MDL is defined as the minimum concentration of a substance that can be measured and reported with a $99 \%$ confidence that the analyte concentration is greater than zero. The MDL is determined from the replicate analysis of a sample in a given matrix containing the analyte.

The analytical method was validated in terms of selectivity, linearity, LOD, LOQ, MDL repeatability, precision and accuracy. 


\subsection{Statistical Analysis}

Once the results from the identification and quantification of the selected analytes and the results from the determination of the physicochemical parameters were obtained from the monitoring study, they were analysed using the software PASW Statistics 18 (SPSS Inc., Chicago, IL, USA) to identify statistically significant trends in the drug concentrations. The effects of the weather conditions, sampling site characteristics (rural and urban areas), sampling date and physical and chemical parameters (nitrites, ammonium, conductivity, turbidity and $\mathrm{pH}$ ) of the water samples collected were tested using one-way ANOVA $(p<0.05)$.

\section{Results and Discussion}

\subsection{Optimisation of the HPLC-MS/MS and Extraction Protocols}

Initially, the method employed by Nebot et al. [36] was selected for the analysis of the collected samples. However, based on the capability of a Synergy-Polar column in the laboratory, this column was selected to perform the analysis instead of a Luna column. This change of the chromatographic columns could explain the results obtained for the paracetamol peak, which did not have a Gaussian shape. The results of the analysis of this compound consequently had to be discarded. More compounds were also included in the method (brilliant green, cefalexin, difloxacin, enrofloxacin, gentian violet, leucomalachite green, malachite green, marbofloxacin, norfloxacin, oxolinic acid, sarafloxacin and triamcinolone). The mobile phase employed was different: methanol and water acidified with formic acid instead of ammonium acetate was employed because the best peak resolution and peak shape were achieved with a combination of these solvents. Formic acid aided in the prevention of peak tailing and provided sufficient ionisation [38,39]. The reproducibility of the $t_{R}$ of the selected drugs was evaluated through the RSDs, and their values were in the range between $0.44 \%$ and $5.40 \%$.

The SPE protocol described by Nebot et al. [36] was initially employed but for the final method some modification were applied. The cartridges were conditioned with $1 \mathrm{~mL}$ less of methanol and water, the sample flow was the same but the elution of the drugs was conducted differently. Methanol alone was employed instead of acetone and methanol because a larger number of analytes were recovered. Instead of $2 \mathrm{~L}$ of sample, a volume of $500 \mathrm{~mL}$ was employed to spend as little time as possible during extraction and to avoid product degradation due to the laboratory conditions. The acidification of the water samples to $\mathrm{pH} 3$ with $1 \mathrm{~N} \mathrm{HCl}$ solution was performed to improve the interaction between the elution solvent and the analytes in the SPE [40]. From 19 pharmaceuticals (brilliant green, cefalexin, diclofenac, difloxacin, enrofloxacin, erythromycin, gentian violet, leucomalachite green, malachite green, marbofloxacin, mefenamic acid, norfloxacin, oxolinic acid, propanolol, sarafloxacin, sulfamethoxazole, tamoxifen, triamcinolone and trimethoprim), a total of 13 analytes were extracted satisfactorily. Recoveries of cefalexin, erythromycin, gentian violet, leucomalachite green, mefenamic acid and norfloxacin could not be taken into account because of their low recoveries. Some steps during the extraction of the fortified samples led to degradation and low recoveries of the analytes. In particular, the $\mathrm{pH}$ adjustment inhibited the extraction of erythromycin and mefenamic acid. Recoveries of trimethoprim, sulfamethoxazole, propanolol, diclofenac and tamoxifen from fortified river water were higher in this study compared to Nebot et al. [36] most likely 
due to a different extraction protocol, but the LOD and LOQ were lower certainly due to lower sample volume. Another factor that could have improved recoveries would be the use of an internal standard, contrasting with the procedure of Nebot et al. [36], who quantified 12 human drugs without the employment of any IS. In this research, the IS sulfadoxine- $\mathrm{d}_{3}$ was employed to quantify the selected drugs in accordance with Hao et al., Hilton et al. and Kasprzyk-Hordern et al. [41-43], who employed one or two ISs to quantify 13 drugs from different therapeutic classes in water samples.

A test was conducted to determine the percent of compound lost during the extraction protocol, in which a battery of water samples was fortified at a concentration of $25 \mathrm{ng} \cdot \mathrm{L}^{-1}$ after the evaporation step. The results showed a loss between $40 \%-50 \%$ of diclofenac, MG, oxolinic acid, propanolol, sulfamethoxazole and tamoxifen during the extraction step.

\subsection{Method Validation}

The selectivity of the method was investigated by comparing the two MRM transitions of the selected analytes obtained from a standard solution, non-fortified river samples and fortified river samples. The method selectivity was demonstrated by noting the absence of interference peaks at the $t_{R}$ of the analytes and IS for both selected transitions.

When a standard solution containing a mixture of the analytes was injected at different concentrations, the IDL obtained ranged from 0.2 to $6.4 \mathrm{ng} \cdot \mathrm{mL}^{-1}$, and the IQL ranged from 0.3 to $6.7 \mathrm{ng} \cdot \mathrm{mL}^{-1}$ (Table 4). A linear response was also observed for concentrations between $1-200 \mathrm{ng} \cdot \mathrm{mL}^{-1}$, with a mean $R^{2}$ higher than 0.991 . The linearity of the whole procedure, samples spiked and extracted as described previously, was observed to have a mean $R^{2}$ above 0.979 for a concentration range between 1 and $200 \mathrm{ng} \cdot \mathrm{L}^{-1}$ (Table 5).

For fortified samples, the LOD was in the range of $1-3.43 \mathrm{ng} \cdot \mathrm{L}^{-1}$, and the LOQ was in the range of 3.0-5.15 $\mathrm{ng} \cdot \mathrm{L}^{-1}$ (Table 4). Although there are reports of lower LODs and LOQs, for example, for tamoxifen $\left(0.03\right.$ and $\left.0.08 \mathrm{~g} \cdot \mathrm{L}^{-1}\right)$ [36], triamcinolone $\left(0.5\right.$ and $\left.1.67 \mathrm{ng} \cdot \mathrm{L}^{-1}\right)$ [44], and marbofloxacin $\left(\mathrm{LOD}=0.8 \mathrm{ng} \cdot \mathrm{L}^{-1}\right)$ [40], other studies present LOD and LOQ values for enrofloxacin $\left(\mathrm{LOD}=34 \mathrm{ng} \cdot \mathrm{L}^{-1}\right.$, $\left.\mathrm{LOQ}=120 \mathrm{ng} \cdot \mathrm{L}^{-1}\right)$ and trimethoprim $\left(\mathrm{LOD}=91 \mathrm{ng} \cdot \mathrm{L}^{-1}, \mathrm{LOQ}=310 \mathrm{ng} \cdot \mathrm{L}^{-1}\right)$ higher than those reported in this work [45] where ion trap MS was used by Dinh et al. [14] for enrofloxacin (LOD $=3.3 \mathrm{ng} \cdot \mathrm{L}^{-1}$, $\left.\mathrm{LOQ}=11 \mathrm{ng} \cdot \mathrm{L}^{-1}\right)$ and oxolinic acid $\left(\mathrm{LOD}=1.7 \mathrm{ng} \cdot \mathrm{L}^{-1}, \mathrm{LOQ}=5.7 \mathrm{ng} \cdot \mathrm{L}^{-1}\right)$ and sarafloxacin $\left(\mathrm{LOD}=1.1 \mathrm{ng} \cdot \mathrm{L}^{-1}, \mathrm{LOQ}=3.6 \mathrm{ng} \cdot \mathrm{L}^{-1}\right)$. Martín et al. and Batt et al. reported LOD and LOQ values for propanolol $\left(\mathrm{LOD}=1 \mathrm{ng} \cdot \mathrm{L}^{-1}, \mathrm{LOQ}=2 \mathrm{ng} \cdot \mathrm{L}^{-1}\right.$ and $\left.\mathrm{LOD}=0.6 \mathrm{ng} \cdot \mathrm{L}^{-1}, \mathrm{LOQ}=2.1 \mathrm{ng} \cdot \mathrm{L}^{-1}\right)[32,46]$, lower than the present work. However, for the compounds diclofenac, sulfamethoxazole and trimethoprim $\left(\mathrm{LOD}=15 \mathrm{ng} \cdot \mathrm{L}^{-1}, \mathrm{LOQ}=49 \mathrm{ng} \cdot \mathrm{L}^{-1}, \mathrm{LOD}=8 \mathrm{ng} \cdot \mathrm{L}^{-1}, \mathrm{LOQ}=28 \mathrm{ng} \cdot \mathrm{L}^{-1}, \mathrm{LOD}=6 \mathrm{ng} \cdot \mathrm{L}^{-1}\right.$, $\left.\mathrm{LOQ}=20 \mathrm{ng} \cdot \mathrm{L}^{-1}\right)$, the values were considerably greater [32]. Data from Ashton et al. [47] showed much higher values than those obtained in this work for sulfamethoxazole, trimethoprim, propanolol, diclofenac and tamoxifen. To the authors' knowledge, no LOD and LOQ values are available for malachite green and brilliant green in surface water to compare with those obtained in this study.

The MDL was calculated for each analyte using river samples fortified with the pharmaceuticals at a concentration of $25 \mathrm{ng} \cdot \mathrm{L}^{-1}$. MDL values for each analyte are summarised in Table 4, and the range was between 2 and $15.1 \mathrm{ng} \cdot \mathrm{L}^{-1}$. The MDL values for diclofenac and sulfamethoxazol achieved during this research were lower than those published by Cahill et al. and Yang et al. [48,49]; Muñóz et al. 
reported the same MDL for propanolol $\left(2 \mathrm{ng} \cdot \mathrm{L}^{-1}\right)$ [50]. However, data obtained for trimethoprim and enrofloxacin were higher than those reported by Senta et al., who achieved MDLs for these compounds between 1-8.5 $\mathrm{ng} \cdot \mathrm{L}^{-1}$ [39]. Batt et al. also report MDLs for sulfamethoxazole and propanolol (5.5 and $1.3 \mathrm{ng} \cdot \mathrm{L}^{-1}$ ) [46], and Kasprzyk-Hordern et al. report an MDL for diclofenac $\left(0.05 \mathrm{ng} \cdot \mathrm{L}^{-1}\right)$ [51]. Once again, no data for malachite green and brilliant green in surface water samples were found.

Table 4. Instrument detection limit (IDL), instrument quantification limit (IQL), limit of detection (LOD), limit of quantification (LOQ) and method detection limit (MDL).

\begin{tabular}{lccccc}
\hline Analyte & IDL $\left(\mathbf{n g} \cdot \mathbf{m L}^{-\mathbf{1}}\right)$ & $\mathbf{I Q L}\left(\mathbf{n g} \cdot \mathbf{m} \mathbf{L}^{-\mathbf{1}}\right)$ & $\mathbf{L O D}\left(\mathbf{n g} \cdot \mathbf{L}^{-\mathbf{1}}\right)$ & $\mathbf{L O Q}\left(\mathbf{n g} \cdot \mathbf{L}^{-\mathbf{1}}\right)$ & $\mathbf{M D L}\left(\mathbf{n g} \cdot \mathbf{L}^{\mathbf{- 1}}\right)$ \\
\hline Brilliant Green & 0.2 & 0.3 & 2.6 & 3.0 & 7.4 \\
Diclofenac & 0.7 & 0.8 & 2.0 & 2.10 & 11.1 \\
Difloxacin & 0.3 & 0.5 & 1.0 & 3.0 & 8.8 \\
Enrofloxacin & 5.4 & 5.8 & 1.37 & 5.15 & 8.1 \\
Malachite Green & 0.2 & 0.3 & 1.5 & 3.3 & 10.9 \\
Marbofloxacin & 0.2 & 0.3 & 1.0 & 3.0 & 8.1 \\
Oxolinic Acid & 6.4 & 6.7 & 3.43 & 3.86 & 9.3 \\
Propanolol & 0.2 & 0.3 & 1.0 & 3.0 & 2.0 \\
Sarafloxacin & 4.6 & 4.8 & 2.1 & 5.2 & 11.9 \\
Sulfamethoxazole & 0.2 & 0.3 & 1.0 & 3.0 & 11.2 \\
Tamoxifen & 0.2 & 0.3 & 2.0 & 3.0 & 13.5 \\
Triamcinolone & 0.9 & 1.1 & 1.0 & 3.0 & 7.6 \\
Trimethoprim & 0.2 & 0.3 & 1.0 & 3.0 & 15.1 \\
\hline
\end{tabular}

Table 5. Regression coefficients $\left(R^{2}\right)$, mean recoveries and relative standard deviation (RSD) of the selected veterinary drugs.

\begin{tabular}{lcccc}
\hline Analyte & ICC R $^{2}$ & SCC R $^{\mathbf{2}}$ & Mean Recovery (\%) & RSD (\%) \\
\hline Brilliant Green & 0.996 & 0.989 & 80 & 20 \\
Diclofenac & 0.999 & 0.999 & 77 & 16 \\
Difloxacin & 0.993 & 0.995 & 60 & 26 \\
Enrofloxacin & 0.997 & 0.979 & 60 & 27 \\
Malachite Green & 0.999 & 0.997 & 79 & 25 \\
Marbofloxacin & 0.991 & 0.986 & 60 & 23 \\
Oxolinic Acid & 0.994 & 0.991 & 62 & 25 \\
Propanolol & 0.999 & 0.999 & 93 & 10 \\
Sarafloxacin & 0.995 & 0.990 & 72 & 20 \\
Sulfamethoxazole & 0.999 & 0.999 & 82 & 25 \\
Tamoxifen & 0.994 & 0.999 & 75 & 20 \\
Triamcinolone & 0.994 & 0.993 & 68 & 22 \\
Trimethoprim & 0.999 & 0.998 & 80 & 21 \\
\hline
\end{tabular}

Notes: ICC: Instrument calibration curve; SCC: Sample calibration curve.

Mean recoveries of the selected drugs are summarised in Table 5, where recoveries higher than $60 \%$ can be observed. The highest recoveries were obtained for brilliant green, propanolol, sulfamethoxazole and trimethoprim with values above $80 \%$ and RSDs lower than $25 \%$. 
Diclofenac, malachite green, sarafloxacin and tamoxifen showed recoveries between $72 \%$ and $79 \%$, and the RSDs were not higher than $25 \%$. The lower recoveries $(60 \%-68 \%)$ corresponded to the quinolone drugs (difloxacin, enrofloxacin, marbofloxacin and oxolinic acid) and triamcinolone with the RSD between $22 \%$ and $27 \%$.

Dinh et al. reported results for recoveries of trimethoprim and sulfamethoxazole (90\% and 94\%) when the spiked level was $200 \mathrm{ng} \cdot \mathrm{L}^{-1}$ [14]. Recoveries for enrofloxacin (83\%) and oxolinic acid (75\%) were higher and for sarafloxacin were similar (79\%). Tamtam et al. obtained, in general, lower recoveries with a spiked level of $100 \mathrm{ng} \cdot \mathrm{L}^{-1}$ in river water samples using UPLC-MS/MS for trimethoprim, sulfamethoxazole, sarafloxacin and difloxacin $(80 \%, 68 \%, 44 \%$ and 55\%) with high RSDs (11\%-29\%) [17]. Recoveries for enrofloxacin were approximately $60 \%$ as in the present study. Other publications reported a range of mean recoveries between $38 \%$ to $88 \%$ for the selected drugs investigated in this study $[39,47,52]$, lower than the values obtained in this research.

\subsection{Monitoring the Presence of Drugs in Spanish Rivers}

Of 549 water samples collected during the two sampling periods, 100 samples (18\%) were positive for the presence of one or more of the selected drugs. The 13 analytes investigated were detected in at least one sample. The mean percentage of positive samples according to the type of area was $17 \%$ in urban areas, $4 \%$ in rural areas with farming activity and $2 \%$ in rural areas without farming activity. Overall, the percentage of positive samples obtained for each sampling period was similar: 19\% and $17 \%$ for the first and the second, even if the number of samples collected was different, 235 (first sampling period) and 314 (second sampling period). When results for each sampling area were compared by sampling period, results were similar, particularly for those samples collected from urban areas. Sampling points located in these areas gave a higher percentage of positive samples: $16 \%$ during the first sampling period and $18 \%$ during the second sampling period. However, we noticed that even if the total percentage of positive samples detected in rural areas did not exceed $6 \%$, during the first sampling period the percent of positive samples was double the percentage of positive samples in the second sampling period. Of all the sampling points located in urban areas, those situated after the discharge point of a WWTP (sites 3 and 13) gave the higher number of positive samples, with a range of detections between $24 \%$ and $33 \%$ of the positive samples and with a percent of detection at each site of $60 \%$ and $80 \%$ for sites 3 and 13 . These results for the area selected from the Galician environment correlated with the results reported by many other authors who detected the presence of pharmaceuticals in surface water samples collected after the discharge of a WWTP $[14,43,53]$. Sites classified as rural areas with low farming activity were the sites with the lowest number of detections but with the highest variation between the different sampling periods. These results support the idea that contamination of the samples analysed comes from human activity.

It should be highlighted that the number of analytes detected was different in each sampling period. In the second sampling period, all the analytes selected for the study were detected in at least one sample. In the first sampling period, only four drugs were measured (diclofenac, marbofloxacin, sulfamethoxazole and trimethoprim). These results could certainly be due to a longer sampling time, as the second period was conducted over seven months while the first was conducted over only three months. Consequently, during the second sampling period, 60 more samples were collected. 
The fact that the second sampling period took longer may have highlighted the influence of livestock in terms of health, feeding or environmental conditions. Weather conditions were also different during the two sampling periods. Mean solar radiation was 70\% higher during the second sampling period, and mean precipitation was $73 \%$ higher during the first sampling period.

Analytes detected and their concentrations are summarised in Table 6 and chromatograms of a surface water sample are represented in Figure 2. If the results are assessed by the type of drugs and their frequency of detection, diclofenac was the drug with more detections in both sampling periods, with 29 (in the first) and 40 (in the second), followed by sulfamethoxazole with nine (in the first) and 33 (in the second) and by trimethoprim with seven (in the first) and 39 (in the second) also the number of detections of sulfamethoxazole and trimethoprim was in the same range for each sampling period, possibly because these drugs are usually administered together in both veterinary and human medicine as they have a synergistic effect. Their high frequency of detection could be due to their frequent use because of their low cost and their broad spectrum of activity to treat bacterial infections [54,55]. Sulfonamides such as sulfamethoxazole and trimethoprim have been detected in surface waters worldwide [56-59]. These results correlated with data reported by Huang et al. who suggested that sulfonamides are the most common water pollutants among various antibiotics based on information concerning their environmental fate and predicted concentrations [60]. Huang et al. predicted that, for example, sulfamethoxazole was most likely to be present in municipal effluent and sulfamethazine in agricultural runoff [60]. Diclofenac is a non-steroidal anti-inflammatory drug (NSAID), commonly used to treat inflammatory rheumatic diseases in humans, so its detection at sites located after the discharge of a WWTP is quite expected and, in fact, this drug was detected in $76 \%$ of the samples $(n=$ $21)$. When the data were treated statistically, significant differences $(p<0.05)$ were found only for sulfamethoxazole and diclofenac according to sampling period. These two analytes were more frequently detected during the second sampling period when their detection was double. When a similar analysis was conducted by sampling month, no significant differences were observed for diclofenac or sulfamethoxazole, but significant differences were observed for trimethoprim. Concentration and frequency of detection of these analytes also showed significant differences $(p<0.05)$ when they were analysed according to sampling points. Site 13 was the site with the highest number of detections: 29 for diclofenac, 24 for trimethoprim, 19 for sulfamethoxazole and 10 for propanolol.

The concentrations of the drugs measured in this research were between 2.8 to $171.4 \mathrm{ng} \cdot \mathrm{L}^{-1}$ (Table 6). Based on the therapeutic class of the drugs, antimicrobial is the group most frequently detected, with 104 detections and a mean concentration of $53.4 \mathrm{ng} \cdot \mathrm{L}^{-1}$. The second group most frequently detected was the anti-inflammatory agent diclofenac, with 69 detections and a mean concentration of 13.6 $\mathrm{ng} \cdot \mathrm{L}^{-1}$, followed by the anti-hypertensive propanolol. The highest concentration of drugs measured during this study corresponded to sarafloxacin but this compound was detected only once, in the sampling site located downstream from the discharge of one WWTP. The detection of sarafloxacin could be due to the entrance of some animal residue into the WWTP because this fluoroquinolone is specially employed in poultry to prevent and treat infections. The drug measured at the second highest concentration $\left(164.5 \mathrm{ng} \cdot \mathrm{L}^{-1}\right)$ was also a fluoroquinolone, enrofloxacin. This sample was collected at one of the sites located in a rural area with farming activity (point 7). This site is surrounded by greenery where cow droppings were found on the bank of the river, most likely due to 
the easy access for grazing livestock to drink water. Like sarafloxacin, the frequency of detection of enrofloxacin was low: enrofloxacin was measured in only three samples collected from three different sites (1, 7 and 13), each site classified differently. Trimethoprim was the analyte measured at the third highest concentration $\left(110.4 \mathrm{ng} \cdot \mathrm{L}^{-1}\right)$. As mentioned earlier, this drug was frequently detected with a mean concentration of $13.8 \mathrm{ng} \cdot \mathrm{L}^{-1}$ in both sampling periods. The highest observed concentration of diclofenac, the compound most frequently detected, was $45.9 \mathrm{ng} \cdot \mathrm{L}^{-1}$, and its mean concentration was $16.6 \mathrm{ng} \cdot \mathrm{L}^{-1}$ in both sampling periods. Jiang et al. published values of concentrations in the same range for sulfamethoxazole $\left(4.86-53.24 \mathrm{ng} \cdot \mathrm{L}^{-1}\right)$ and trimethoprim $\left(2.23-62.39 \mathrm{ng} \cdot \mathrm{L}^{-1}\right)$ in China [61]. Diclofenac was detected in the range of $2.8-46 \mathrm{ng} \cdot \mathrm{L}^{-1}$ in $69 \%$ of the positive samples during this research. A similar frequency of detection was reported by Kasprzyk-Hordern et al. who detected diclofenac in rivers of the UK in the range of $1-261 \mathrm{ng} \cdot \mathrm{L}^{-1}$ at a mean percentage frequency of $74 \%$ [51]. The greater concentration of trimethoprim $\left(110.4 \mathrm{ng} \cdot \mathrm{L}^{-1}\right)$ was detected in a sample collected from a rural site surrounded by bovine livestock farms, specifically dairy cattle. Dinh et al. also reported concentrations for sulfamethoxazole $\left(3.6-1,435 \mathrm{ng} \cdot \mathrm{L}^{-1}\right)$ and trimethoprim $\left(8-254 \mathrm{ng} \cdot \mathrm{L}^{-1}\right)$ downstream of WWTPs [14]. However, if data obtained during this research are compared with concentrations of residues found in surface waters in Spain (up to $20 \mathrm{ng} \cdot \mathrm{L}^{-1}$ ), the United Kingdom (up to $42 \mathrm{ng} \cdot \mathrm{L}^{-1}$ ), South Korea $\left(3.2-5.3 \mathrm{ng} \cdot \mathrm{L}^{-1}\right)$ and in Serbia $\left(25 \mathrm{ng} \cdot \mathrm{L}^{-1}\right)$ [47,62-64], the concentration of the analytes measured in the Galician environment were higher.

Table 6. Maximum, minimum and mean concentrations of the selected drugs detected in Spanish surface water and number of time detected in the samples.

\begin{tabular}{lcccc}
\hline Analyte & $\begin{array}{c}\text { Maximum } \\
\text { concentration }\left(\mathbf{n g} \cdot \mathbf{L}^{-1}\right)\end{array}$ & $\begin{array}{c}\text { Minimum } \\
\text { concentration }\left(\mathbf{n g} \cdot \mathbf{L}^{-1}\right)\end{array}$ & $\begin{array}{c}\text { Mean concentration } \\
\left(\mathbf{n g} \cdot \mathbf{L}^{-1}\right)\end{array}$ & $\begin{array}{c}\text { Number of } \\
\mathbf{d e t e c t i o n s}\end{array}$ \\
\hline Brilliant Green & 7.9 & 3.3 & 5.6 & 2 \\
Diclofenac & 46.0 & 2.8 & 13.6 & 69 \\
Difloxacin & 8.5 & 8.5 & 8.5 & 1 \\
Enrofloxacin & 164.5 & 60.0 & 119.9 & 3 \\
Malachite Green & 9.0 & 9.0 & 9.0 & 1 \\
Marbofloxacin & 20.1 & 3.6 & 8.8 & 10 \\
Oxolinic Acid & 39.1 & 39.1 & 39.1 & 1 \\
Propanolol & 62.6 & 4.2 & 11.5 & 14 \\
Sarafloxacin & 171.4 & 171.4 & 171.4 & 1 \\
Sulfamethoxazole & 40.1 & 3.0 & 10.7 & 42 \\
Tamoxifen & 11.7 & 3.5 & 7.5 & 6 \\
Triamcinolone & 8.4 & 8.4 & 8.4 & 1 \\
Trimethoprim & 110.4 & 3.5 & 16.1 & 46 \\
\hline
\end{tabular}

Another active compound frequently detected during this research was propanolol, which is a beta blocker drug involved mainly in relaxing blood vessels and decreasing heart rate to improve blood flow and lower blood pressure. Propanolol was detected in 14 samples in the range of $4.2-62.6 \mathrm{ng} \cdot \mathrm{L}^{-1}$, similar to the values reported by Kasprzyk-Hordern et al. (3-91 $\left.\mathrm{ng} \cdot \mathrm{L}^{-1}\right)$ in the rivers of the UK [51] and higher than the values measured by Alder et al. in Switzerland (7-8 ng. $\left.\mathrm{L}^{-1}\right)$ [13]. The highest concentration of propanolol found during this work $\left(37.4 \mathrm{ng} \cdot \mathrm{L}^{-1}\right)$ was measured in a sample collected 
at a site described as a rural area. Most of the detections of this compound occurred at the sites located after the discharge of the WWTPs, most likely due to low removal during treatment at the WWTP as reported by Gros et al. who observed a rate of removal for this compound below 20\% [65]. These results are in accordance with data published by Martín et al., who detected propanolol in 100\% of the samples collected downstream of discharge from four WWTPs [32]. The range of concentrations reported for this compound was between 30 to $720 \mathrm{ng} \cdot \mathrm{L}^{-1}$, ten times higher than the concentrations measured in the River Miño. However, the area investigated was more or less than ten times less populated than the Guadalquivir area studied by Martín et al. [32]. As these drugs are not allowed in food-producing animals, the presence of propanolol in a sample collected from a rural area could be due to its application to animals not dedicated to food production, or the presence of this compound could also be due to a leak from the septic tanks.

Figure 2. MRM chromatograms for sulfamethoxazole $\left(37.7 \mathrm{ng} \cdot \mathrm{L}^{-1}\right)$, trimethoprim $\left(64.3 \mathrm{ng} \cdot \mathrm{L}^{-1}\right)$ and diclofenac $\left(31.4 \mathrm{ng} \cdot \mathrm{L}^{-1}\right)$ detected in galician surface water.

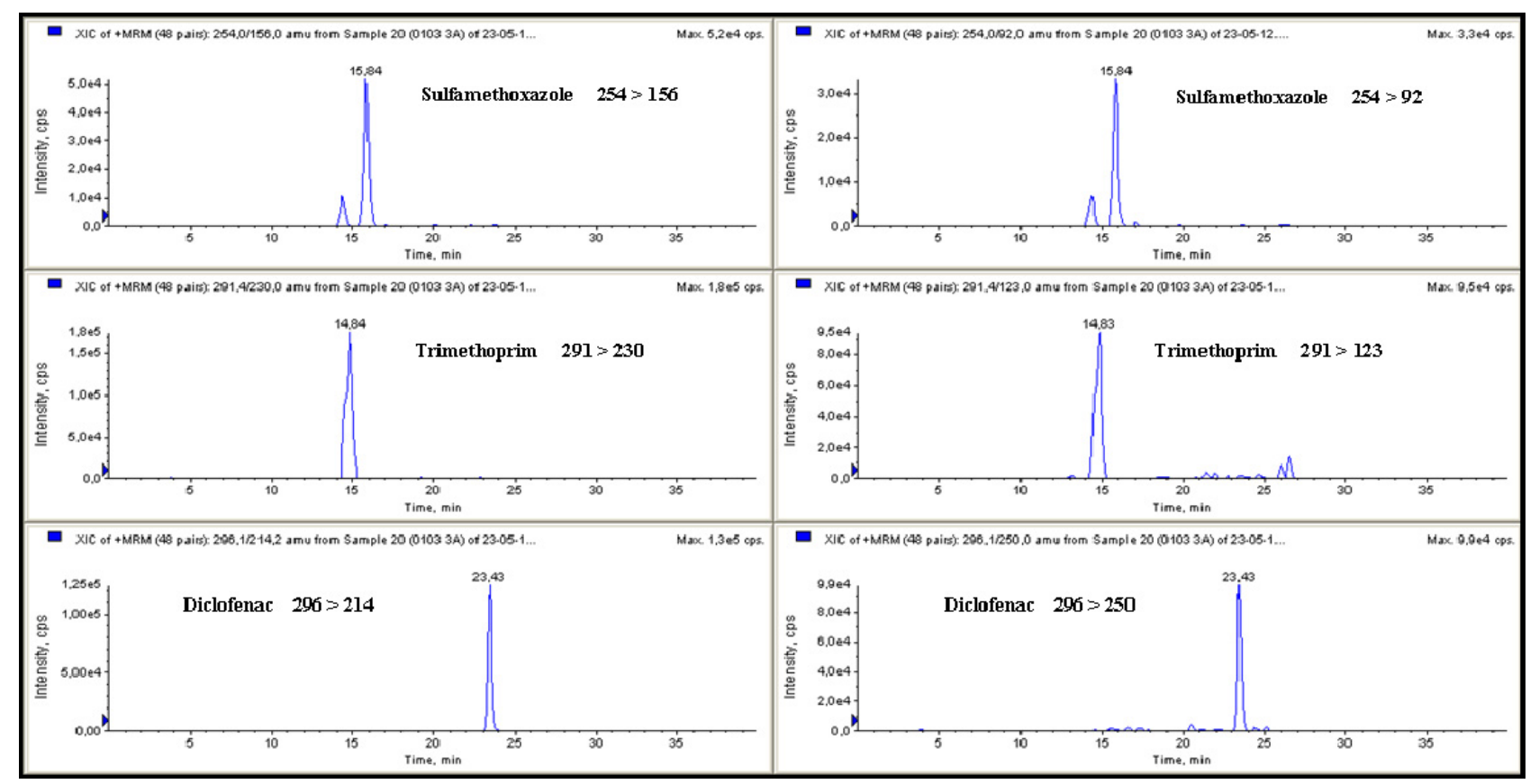

The antimicrobial marbofloxacin was detected with a range in concentration from 3.6 to $20.1 \mathrm{ng} \cdot \mathrm{L}^{-1}$, where the highest value was found at a rural site (point 1) located in the Miño River flow. The second greatest concentration was detected at a site also located in the Miño River but on its way through the city of Lugo (point 12). The rest of the analytes selected in this study were detected at a percentage less than $10 \%$. Like sarafloxacin, oxolinic acid was detected only once $\left(39.1 \mathrm{ng} \cdot \mathrm{L}^{-1}\right)$ in a sample collected at a site located near the discharge of a WWTP (point 13). Oxolinic acid had also been found in the Seine River at a similar concentration $\left(23 \mathrm{ng} \cdot \mathrm{L}^{-1}\right)$ by Dinh et al. [14].

The presence of the triphenylmethane dyes, brilliant green and malachite green, in the Galician water is a matter for further study, even if brilliant green was detected only twice and malachite green once in concentrations that do not exceed $9.0 \mathrm{ng} \cdot \mathrm{L}^{-1}$. As previously mentioned, these compounds are multi-organ toxics to mammals that show serious negative effects [5]. The detections of these two compounds were at the same sampling site, with two of them observed on the same day. 
The compounds were found at a site located near the discharge of the WWTP located at site number 13, flowing downstream of the city of Lugo. The hypothesis is that these residues could originate from a paper industry located on the upper side of the city and perhaps be swept away by the Miño River to be found in such low concentrations on the lower side or maybe due to the fish farms that are located near the city of Lugo, but this is only a hypothesis because the use of these drugs is forbidden for processing of all categories of edible fish, including fish eggs.

For each collected sample, physicochemical parameters such as nitrites, ammonium, conductivity, turbidity and $\mathrm{pH}$ were measured. Statistical analysis (ANOVA and a linearity test) was conducted for the concentration of the analytes and these parameters. However, no significant differences $(p<0.05)$ were found for ammonium, nitrites, conductivity, turbidity and $\mathrm{pH}$. When statistical analysis was conducted with weather conditions (mean temperature $\left({ }^{\circ} \mathrm{C}\right)$, mean precipitation $(\mathrm{mm})$, mean humidity $(\%)$ and mean solar radiation $\left.\left(10 \mathrm{~kJ} / \mathrm{m}^{2}\right)\right)$, significant differences $(p<0.05)$ were observed for diclofenac and mean temperature. Samples that contained a measurable concentration of diclofenac were collected on days when the temperature was equal to or above $15{ }^{\circ} \mathrm{C}$. Diclofenac was more frequently detected in samples collected in urban areas, especially after the discharge of a WWTP, but in the samples collected from rural areas, diclofenac was detected on days when the mean temperature was above $17{ }^{\circ} \mathrm{C}$, most likely because treated animals were put out to pasture. Significant differences $(p<0.05)$ were also observed for propanolol concentration and precipitation. This analyte was generally detected on days when rainfall was not registered. The lack of detection on rainy days could have being due to a dilution effect, as most samples contained a concentration of propanolol below $10 \mathrm{ng} \cdot \mathrm{L}^{-1}$. No significant differences $(p<0.05)$ were found for any of the drugs and mean humidity, but significant differences were observed for diclofenac concentration and mean solar radiation. Similarly to mean temperature, those positive samples for diclofenac that were collected in rural areas were collected on days with low mean solar radiation. As demonstrated by Bartels et al. [66], diclofenac is sensitive to solar radiation, and its concentration decreased with solar radiation. Based on these findings, diclofenac could have been liberated into the Galician environment, and its frequency of detection in this study could have been higher but solar radiation helped to decrease its concentration to undetectable levels with the method employed.

This study has demonstrated that even if Galicia is an area of Spain with high rainfall and low population density compared with other areas of Spain, the presence of active compounds such as pharmaceuticals in the aquatic environment is common, and these results were similar to results published for other areas of Spain such as Catalonia, the Spanish Mediterranean area, Valencia, Madrid and Sevilla [27,29,30,32,33,67]. Although drug concentrations were below $200 \mathrm{ng} \cdot \mathrm{L}^{-1}$ (Table 6), toxic effects of these compounds in non-target organisms have previously been reported. Potential toxicity affected plants and soil organisms due to sulfamethoxazole $[8,68]$ and freshwater crustaceans and fish as a result of their exposure to propanolol and diclofenac $[9,69]$. Based on these findings reported by other authors and results obtained for samples collected at sites located next to the collection point of a drinking water treatment plant, more than $5 \%$ of the samples collected at this site were positive for the analysed active compounds, causing significant concern. 


\section{Conclusions}

The occurrence of drugs in the aquatic environment has recently become a matter of concern. This work presents a suitable HPLC-ESI-MS/MS method for the simultaneous extraction, detection and quantification of residues of 13 active substances (antimicrobials, glucocorticosteroids, non steroidal anti-inflammatories, anti-hypertensives, anti-cancer drugs and triphenylmethane dyes) in fresh water. In-house validation according to EPA guidelines makes this method suitable for government or private laboratories dedicated to investigating the presence of drugs in the aquatic environment. The method was also employed to conduct a monitoring study for the presence of the selected analytes in the Galician region with 549 water samples. All the analytes were detected and in a range of concentrations between 2.8 and $171.4 \mathrm{ng} \cdot \mathrm{L}^{-1}$. Even if the number of sampling sites located in rural areas (with and without farming activity) was more than double the number of sampling sites located in urban areas, more positive samples were obtained in samples collected from sites located in urban areas, in particular, sites located after the discharge of a WWTP. Rural areas with farming activities also had positive samples but always at a percentage below $15 \%$ of the samples collected. The relationship between concentrations and environmental conditions, physicochemical parameters, dates and sampling points were statistically tested, and significant differences were observed only for diclofenac and temperature and solar radiation and between propanolol and precipitation. Based on these results, active compounds are also present in the Galician environment and even if farming activities are conducted in an area, the WWTPs act as a concentration point.

\section{Acknowledgments}

The authors wish to thank the Fondo Europeo Agrícola de Desarrollo Rural (FEADER) and the Consellería de Medio Rural for funding this study through the project FMR331A, and the staff of the Cactus of the University of Santiago de Compostela for their help in the analysis of the samples.

\section{Author Contributions}

Alberto Cepeda and Carlos Franco conceived the study idea, contributed to study design and contributed to manuscript revision. Beatriz Vázquez and Claudia Coronel-Olivares collected data and contributed to manuscript revision. Alejandra Iglesias and Carolina Nebot carried out the experimental work and data analysis and also wrote the original manuscript.

\section{Conflicts of Interest}

The authors declare no conflict of interest.

\section{References}

1. Fent, K.; Anna, A.; Weston, A.A.; Caminada, D. Ecotoxicology of human pharmaceuticals. Aquat. Toxicol. 2006, 76, 122-159.

2. Kemper, N. Veterinary antibiotics in the aquatic and terrestrial environment. Ecol. Indic. 2008, 8, $1-13$. 
3. Crane, M.; Boxall, A.B.A.; Barrett, K. Veterinary Medicines in the Environment; Crane, M., Boxall, A.B.A., Barret, K., Eds.; Taylor \& Francis: Boca Raton, FL, USA/CRC Press: London, UK, 2009; p. 224.

4. Bergwerff, A.A.; Scherpenisse, P. Determination of residues of malachite green in aquatic animals. J. Chromatogr. B 2003, 788, 351-359.

5. Oplatowska, M.; Donnelly, R.F.; Majithiya, R.J.; Kennedy, D.G.; Elliott, C.T. The potential for human exposure, direct and indirect, to the suspected carcinogenic triphenylmethane dye Brilliant Green from green paper towels. Food Chem. Toxicol. 2011, 49, 1870-1876.

6. Srivastava, S.; Sinha, R.; Roy, D. Toxicological effects of malachite green. Aquat. Toxicol. 2004, 66, 319-329.

7. Daughton, C.G.; Ternes, T.A. Pharmaceuticals and personal care products in the environment, agents of subtle change? Environ. Health Perspect. 1999, 107, 907-938.

8. Jung, J.; Kim, Y.; Kim, J.; Jeong, D.H.; Choi, K. Environmental levels of ultraviolet light potentiate the toxicity of sulfonamide antibiotics in Daphnia magna. Ecotoxicology 2008,17, 37-45.

9. Kim, J.W.; Ishibashi, H.; Yamauchi, R.; Ichikawa, N.; Takao, Y.; Hirano, M.; Koga, M.; Arizono, K. Acute toxicity of pharmaceutical and personal care products on freshwater crustacean (Thamnocephalus platyurus) and fish (Oryzias latipes). J. Toxicol. Sci. 2009, 34, 227-232.

10. Li, Z.H.; Randak, T. Residual pharmaceutically active compounds (PhACs) in aquatic environment-Status, toxicity and kinetics, a review. Vet. Med.-Czech. 2009, 54, 295-314.

11. Madureira, T.V.; Cruzeiro, C.; Rochaa, M.J.; Rocha, E. The toxicity potential of pharmaceuticals found in the Douro River estuary (Portugal)_Experimental assessment using a zebrafish embryo test. Environ. Toxicol. Pharmacol. 2011, 32, 212-217.

12. Heberer, T.; Fuhrmann, B.; Schmidt-Baumler, K.; Tsipi, D.; Koutsouba, V.; Hiskia, A. Occurrence of pharmaceutical residues in sewage, river, ground, and drinking water in Greece and Berlin (Germany). In Pharmaceuticals and Care Products in the Environment: Scientific and Regulatory Issues; Daughton, C.G., Jones-Lepp, T.L., Eds.; American Chemical Society: Washington, DC, USA, 2001; pp. 70-83.

13. Alder, A.C.; Schaffner, C.; Majewsky, M.; Klasmeier, J.; Fenner, K. Fate of b-blocker human pharmaceuticals in surface water: Comparison of measured and simulated concentrations in the Glatt Valley Watershed, Switzerland. Water Res. 2010, 44, 936-948.

14. Dinh, Q.T.; Alliot, F.; Moreau-Guigon, E.; Eurin, J.; Chevreuil, M.; Labadie, P. Measurement of trace levels of antibiotics in river water using on-line enrichment and triple-quadrupole LC-MS/MS. Talanta 2011, 85, 1238-1245.

15. Ferrer, I.; Zweigenbaum, J.A.; Thurman, E.M. Analysis of 70 Environmental Protection Agency priority pharmaceuticals in water by EPA Method 1694. J. Chromatogr. A 2010, 1217, 5674-5686.

16. Minh, T.B.; Leung, H.W.; Loi, I.H.; Chan, W.H.; Som, M.K.; Maob, J.Q.; Choi, D.; Lam, J.C.W.; Zheng, G.; Martín, M.; et al. Antibiotics in the Hong Kong metropolitan area: Ubiquitous distribution and fate in Victoria Harbour. Mar. Pollut. Bull. 2009, 58, 1052-1062.

17. Tamtam, F.; Mercier, F.; Eurin, J.; Chevreuil, M.; le Bot, B. Ultra performance liquid chromatography tandem mass spectrometry performance evaluation for analysis of antibiotics in natural waters. Anal. Bioanal. Chem. 2009. 393, 1709-1718. 
18. Zuccato, E.; Castiglioni, S.; Bagnati, R.; Melis, M.; Fanelli, R. Source, occurrence and fate of antibiotics in the Italian aquatic environment. J. Hazard. Mater. 2010, 179, 1042-1048.

19. Carpinteiro, J.; Quintana, J.B.; Martínez, E.; Rodríguez, I.; Carro, A.M.; Lorenzo, R.A.; Cela, R. Application of strategic sample composition to the screening of anti-inflammatory drugs in water samples using solid-phase microextraction. Anal. Chim. Acta 2004, 524, 63-71.

20. Castro-Puyana, M.; Crego, A.L.; Marina, M.L. Recent advances in the analysis of antibiotics by $\mathrm{CE}$ and CEC. Electrophoresis 2010, 31, 229-250.

21. Herrera-Herrera, A.V.; Ravelo-Péreza, L.M.; Hernández-Borgesa, J.; Afonso, M.M.; Palenzuela, J.A.; Rodríguez-Delgado, M.A. Oxidized multi-walled carbon nanotubes for the dispersive solid-phase extraction of quinolone antibiotics from water samples using capillary electrophoresis and large volume sample stacking with polarity switching. J. Chromatogr. A 2011, 1218, 5352-5361.

22. Lin, C.Y.; Huang, S.D. Application of liquid-liquid-liquid microextraction and high-performance liquid-chromatography for the determination of sulfonamides in water. Anal. Chim. Acta 2008, 612, 37-43.

23. Raich-Montiu, J.; Folch, J.; Compañó, R.; Granados, M.; Prat, M.D. Analysis of trace levels of sulfonamides in surface water and soil samples by liquid chromatography-fluorescence. J. Chromatogr. A 2007, 1172, 186-193.

24. Serrano, J.M.; Silva, M. Rapid and sensitive determination of aminoglycoside antibiotics in water samples using a strong cation-exchange chromatography non-derivatisation method with chemiluminescence detection. J. Chromatogr. A 2006, 1117, 176-183.

25. Sun, L.; Chen, L.; Sun, X.; Du, X.; Yue, Y.; He, D.; Xu, H.; Zeng, Q.; Wang, H.; Ding, L. Analysis of sulfonamides in environmental water samples based on magnetic mixed hemimicelles solid-phase extraction coupled with HPLC-UV detection. Chemosphere 2009, 77, 1306-1312.

26. Díaz-Cruz, M.S.; García-Galán, M.J.; Barceló, D. Highly sensitive simultaneous determination of sulfonamide antibiotics and one metabolite in environmental waters by liquid chromatography-quadrupole linear ion trap-mass spectrometry. J. Chromatogr. A 2008, 1193, 50-59.

27. García-Galán, M.J.; Díaz-Cruz, M.S.; Barceló, D. Determination of 19 sulfonamides in environmental water samples by automated on-line solid-phase extraction-liquid chromatography-tandem mass spectrometry (SPE-LC-MS/MS). Talanta 2010, 81, 355-366.

28. Huerta-Fontela, M.; Galceran, M.T.; Ventura, F. Ultraperformance liquid chromatography-tandem mass spectrometry analysis of stimulatory drugs of abuse in wastewater and surface waters. Anal. Chem. 2007, 79, 3821-3829.

29. Ibáñez, M.; Guerrero, C.; Sancho, J.V.; Hernández, F. Screening of antibiotics in surface and wastewater samples by ultra-high-pressure liquid chromatography coupled to hybrid quadrupole time-of-flight mass spectrometry. J. Chromatogr. A 2009, 1216, 2529-2539.

30. Kuster, M.; López de Alda, M.J.; Hernando, M.D.; Petrovic, M.; Martín-Alonso, J.; Barceló, D. Analysis and occurrence of pharmaceuticals, estrogens, progestogens and polar pesticides in sewage treatment plant effluents, river water and drinking water in the Llobregat river basin (Barcelona, Spain). J. Hydrol. 2008, 358, 112-123.

31. Pedrouzo, M.; Borrull, F.; Marcé, R.M.; Pocurull, E. Simultaneous determination of macrolides, sulfonamides, and other pharmaceuticals in water samples by solid-phase extraction and LC-(ESI) MS. J. Sep. Sci. 2008, 31, 2182-2188. 
32. Martín, J.; Camacho-Muñóz, D.; Santos, J.L.; Aparicio, I.; Alonso, E. Monitoring of pharmaceutically active compounds on the Guadalquivir River basin (Spain): Occurrence and risk assessment. J. Environ. Monit. 2011, 13, 2042-2049.

33. Valcárcel, Y.; González Alonso, S.; Rodríguez-Gil, J.L.; Gil, A.; Catalá, M. Detection of pharmaceutically active compounds in the rivers and tap water of the Madrid Region (Spain) and potential ecotoxicological risk. Chemosphere 2011, 84, 1336-1348.

34. González-Mariño, I.; Quintana, J.B.; Rodríguez, I.; Cela, R. Determination of drugs of abuse in water by solid-phase extraction, derivatisation and gas chromatography-ion trap-tandem mass spectrometry. J. Chromatogr. A 2010, 1217, 1748-1760.

35. Cancel-Barrio, J.J.; Fandiño, M. Management of irrigation water in Terra Chá: Indicators (In Spanish). IBADER 2009, 5, 49-57.

36. Nebot, C.; Gibb, S.W.; Boyd, K.G. Quantification of human pharmaceuticals in water samples by high performance liquid chromatography-tandem mass spectrometry. Anal. Chim. Acta 2007. 598, 87-94.

37. Environmental Protection Agency (EPA). Definition and Procedure for the Method Detection Limit-Revision 136, Appendix B; EPA-Environmental Protection Agency: Washington, DC, USA, 1984.

38. Kim, S.C.; Carlson, K. Quantification of human and veterinary antibiotics in water and sediment using SPE/LC/MS/MS. Anal. Bioanal. Chem. 2007, 387, 1301-1315.

39. Senta, I.; Terzic, S.; Ahel, M. Simultaneous determination of sulfonamides, fluoroquinolones, macrolides and trimethoprim in wastewater and river water by LC-tandem-MS. Chromatographia 2008, 68, 747-758.

40. Pozo, O.J.; Guerrero, C.; Sancho, J.V.; Ibáñez, M.; Pitarch, E.; Hogendoorn, E.; Hernández. F. Efficient approach for the reliable quantification and confirmation of antibiotics in water using on-line solidphase extraction liquid chromatography/tandem mass spectrometry. J. Chromatogr. A 2006, 1103, 83-93.

41. Hao, C.; Lissemore, L.; Nguyen, B.; Kleywegt, S.; Yang. P.; Solomon, K. Determination of pharmaceuticals in environmental waters by liquid chromatography/electrospray ionization/tandem mass spectrometry. Anal. Bioanal. Chem. 2006, 384, 505-513.

42. Hilton, M.; Thomas, K.V. Determination of selected human pharmaceutical compounds in effluent and surface water samples by high-performance liquid chromatography-Electrospray tandem mass spectrometry. J. Chromatogr. A 2003, 1015, 129-141.

43. Kasprzyk-Hordern, B.; Dinsdale, R.M.; Guwy, A.J. Multi-residue method for the determination of basic/neutral pharmaceuticals and illicit drugs in surface water by solid-phase extraction and ultra performance liquid chromatography-positive electrospray ionization tandem mass spectrometry. J. Chromatogr. A 2007, 1161, 132-145.

44. Tölgyesi, A.; Verebey, Z.; Sharma, V.K.; Kovacsics, L.; Fekete, J. Simultaneous determination of corticosteroids, androgens, and progesterone in river water by liquid chromatography-tandem mass spectrometry. Chemosphere 2010, 78, 972-979.

45. Batt, A.L.; Aga, D.S. Simultaneous analysis of multiple classes of antibiotics by ion trap LC/MS/MS for assessing surface water and groundwater contamination. Anal. Chem. 2005, 77, 2940-2947. 
46. Batt, A.L.; Kostich, M.S.; Lazorchak, J.M. Analysis of ecologically relevant pharmaceuticals in wastewater and surface water using selective solid-phase extraction and UPLC-MS/MS. Anal. Chem. 2008, 80, 5021-5030.

47. Ashton, D.; Hilton, M.; Thomas, K.V. Investigating the environmental transport of human pharmaceuticals to streams in the United Kingdom. Sci. Total Environ. 2004, 333, 167-184.

48. Cahill, J.D.; Furlong, E.T.; Burkhardt, M.R.; Kolpin, D.; Anderson, L.G. Determination of pharmaceutical compounds in surface- and ground-water samples by solid-phase extraction and high-performance liquid chromatography-electrospray ionization mass spectrometry. J. Chromatogr. A 2004, 1041, 171-180.

49. Yang, S.; Cha, J.; Carlson, K.H. Quantitative determination of trace concentrations of tetracycline and sulfonamide antibiotics in surface water using solid-phase extraction and liquid chromatography/ion trap tandem mass spectrometry. Rapid Commun. Mass 2004, 18, 2131-2145.

50. Muñóz, I.; López-Doval, J.C.; Ricart, M.; Villagrasa, M.; Brix, R.; Geiszinger, A.; Ginebreda, A.; Guasch, H.; López de Alda, M.J.; Romaní, A.M.; et al. Bridging levels of pharmaceuticals in river water with biological community structure in the Llobregat river basin (northeast Spain). Environ. Toxicol. Chem. 2009, 28, 2706-2714.

51. Kasprzyk-Hordern, B.; Dinsdale, R.M.; Guwy, A.J. The occurrence of pharmaceuticals, personal care products, endocrine disruptors and illicit drugs in surface water in South Wales, UK. Water Res. 2008, 42, 3498-3518.

52. Benito-Peña, E.; Urraca, J.L.; Sellergren, B.; Moreno-Bondi, M.C. Solid-phase extraction of fluoroquinolones from aqueous samples using a water-compatible stochiometrically imprinted polymer. J. Chromatogr. A 2008, 1208, 62-70.

53. Rao, R.N.; Venkateswarlu, N.; Narsimha, R. Determination of antibiotics in aquatic environment by solid-phase extraction followed by liquid chromatography-electrospray ionization mass spectrometry. J. Chromatogr. A 2008, 1187, 151-164.

54. Forbes, B.; Sahm, D.F.; Weissfeld, A.S. Bailey \& Scott's Diagnostic Microbiology, 12th ed.; Médica Panamericana: Argentina, Spian, 2009; p.1026.

55. Pastor-Navarro, N.; Maquieira, Á.; Puchades, R. Review on immunoanalytical determination of tetracycline and sulfonamide residues in edible products. Anal. Bioanal. Chem. 2009, 395, 907-920.

56. Ferguson, P.J.; Bermot, M.J.; Doll, J.C.; Lauer, T.E. Detection of pharmaceuticals and personal care products (PPCPs) in near-shore habitats of southern Lake Michigan. Sci. Total. Environ. 2013, 458, 187-196.

57. Gros, M.; Rodríguez-Mozaz, S.; Barceló, D. Fast and comprehensive multi-residue analysis of a broad range of human and veterinary pharmaceuticals and some of their metabolites in surface and treated waters by ultra-high-performance liquid chromatography coupled to quadrupole-linear ion trap tandem mass spectrometry. J. Chromatogr. A 2012, 1248, 104-121.

58. Park, J. Pharmaceuticals in the Environment and Management Approaches in Korea; Korea Environment Institute: Seoul, Korea, 2005.

59. Yang, J.F.; Ying, G.G.; Zhao, J.L.; Tao, R.; Su, H.C.; Liu, Y.S. Spatial and seasonal distribution of selected antibiotics in surface waters of the Pearl Rivers, China. J. Environ. Sci. Health B 2011, $46,272-280$. 
60. Huang, C.H.; Renew, J.E.; Smeby, K.L.; Pinkston, K.; Sedlak, D.L. Assessment of potential antibiotic contaminants in water and preliminary occurrence analysis. J. Contemp. Water Res. Educ. 2011, 120, 30-40.

61. Jiang, L.; Hu, X.; Yin, D.; Zhang, H.; Yu, Z. Occurrence, distribution and seasonal variation of antibiotics in the Huangpu River, Shanghai, China. Chemosphere 2011, 82, 822-828.

62. Gros, M.; Petrovic, M.; Barceló, D. Development of a multi-residue analytical methodology based on liquid chromatography-tandem mass spectrometry (LC-MS/MS) for screening and trace level determination of pharmaceuticals in surface and wastewaters. Talanta 2006, 70, 678-690.

63. Kim, S.D.; Cho, J.; Kim, I.S.; Vanderford, B.J.; Snyder, S.A. Occurrence and removal of pharmaceuticals and endocrine disruptors in South Korean surface, drinking, and waste waters. Water Res. 2007, 41, 1013-1021.

64. Grujíc, S.; Vasiljevic, T.; Lausevic, M. Determination of multiple pharmaceutical classes in surface and ground waters by liquid chromatography-ion trap-tandem mass spectrometry. J. Chromatogr. A 2009, 1216, 4989-5000.

65. Gros, M.; Petrović, M.; Ginebreda, A.; Barceló, D. Removal of pharmaceuticals during wastewater treatment and environmental risk assessment using hazard indexes. Environ. Int. 2010, $36,15-26$.

66. Bartels, P.; Tümpling, W.V. Solar radiation influence on the decomposition process of diclofenac in surface waters. Sci. Total Environ. 2007, 374, 143-155.

67. Farré, M.; Ferrer, I.; Ginebreda, A.; Figueras, M.; Olivella, L.; Tirapu, L.; Vilanova, M.; Barceló, D. Determination of drugs in surface water and wastewater samples by liquid chromatography-mass spectrometry: Methods and preliminary results including toxicity studies with Vibrio fischeri. J. Chromatogr. A 2001, 938, 187-97.

68. Isidori, M.; Lavorgna, M.; Nardelli, A.; Pascarella, L.; Parrella, A. Toxic and genotoxic evaluation of six antibiotics on non-target organisms. Sci. Total Environ. 2005, 346, 87-98.

69. Schwaiger, J.; Ferling, H.; Mallow, U.; Wintermayr, H.; Negele, R.D. Toxic effects of the non-steroidal anti-inflammatory drug diclofenac. Part I: Histopathological alterations and bioaccumulation in rainbow trout. Aquat. Toxicol. 2004, 68, 141-150.

(C) 2014 by the authors; licensee MDPI, Basel, Switzerland. This article is an open access article distributed under the terms and conditions of the Creative Commons Attribution license (http://creativecommons.org/licenses/by/3.0/). 